\title{
A HIPÓTESE DO CAPITALISMO DISFORME NO CAMPO: DIALÉTICA DO PROGRESSO NA RELAÇÃO ENTRE AGRICULTURA E CAPITALISMO EM UM TEXTO DE KARL MARX
}

\author{
A CASE OF FORMLESS CAPITALISM IN THE FIELD: DIALECTIC OF \\ PROGRESS IN AGRICULTURE AND RELATION BETWEEN CAPITALISM \\ IN A STRING OF KARL MARX
}

\section{UN CASO DEL CAPITALISMO SIN FORMA EN EL CAMPO: DIALÉCTICA DEL PROGRESO EN LA AGRICULTURA Y LA RELACIÓN ENTRE EL CAPITALISMO EN UNA CADENA DE KARL MARX}

\author{
Deni Ireneu Alfaro Rubbo* \\ deni_out27@uol.com.br
}

\begin{abstract}
Resumo: O objetivo mais geral deste texto é ensaiar uma primeira aproximação sobre a evolução e a contextualização da produção do texto de Marx, a partir de sua obra de maior fôlego, $O$ capital - exclusivamente no Livro III e especialmente na seção da renda fundiária -, que está irredutivelmente marcada por uma construção inconclusa. Pretende-se acumular e detalhar algumas considerações teórico-metodológicas, isto é, precauções para "evitar mal-entendidos", tal como assinalou Marx, levadas a cabo mais sistematicamente no capítulo 37. A hipótese central é a de que o tema da renda da terra é construído a partir de uma representação não linear do desenvolvimento histórico, principalmente por uma abordagem que inclui uma crítica da noção abstrata do progresso e da relação de desenvolvimento desigual e combinado, o que pode servir como ponto de partida para os problemas contemporâneos entre agricultura e capitalismo, principalmente nos assim chamados sistemas capitalistas subnacionais periféricos. Tal construção desautorizaria de uma vez por todas a compreensão dessas passagens críticas como categorias eternas, típicas das visões lineares e otimistas do marxismo positivista.
\end{abstract}

Palavras-chave: Marx, renda fundiária, crítica do progresso, capitalismo disforme.

Abstract: The general objective of this paper is to test a first approximation on the evolution and context of text production of Marx, from his work as a longer-term Capital, solely in Book III, and even more, especially the section of ground rent - that is irreducibly marked by an unfinished building. In this opportunity, we intend to accumulate and to detail some theoretical and methodological considerations, i.e., precautions "to avoid misunderstandings", as Marx pointed out, carried out more systematically in Chapter 37. The central hypothesis is that the issue of ground rent is constructed from a nonlinear representation of historical development, especially for an approach that includes a critique of the abstract notion of progress and the relationship of combined and uneven development, which can serve as a starting point for the contemporary problems of agriculture and capitalism, especially in so-called sub-peripheral capitalist systems. Such construction disqualify once and for all the understanding of these critical passages as eternal categories, typical of linear and optimistic visions of the marxist positivist.

\footnotetext{
O tema abordado deriva de uma aproximação com a nossa pesquisa em andamento que pretende, em linhas bem gerais, a partir do fenômeno da internacionalização do MST - que se manifesta concretamente com a CLOC e a Via Campesina - traçar paralelos com a política internacionalista de esquerda e a recepção (no âmbito do marxismo) que teve no continente latino-americano.

Mestrando em Sociologia pela FFLCH-USP e bolsista Capes.
} 
Keywords: Marx, land rent, review of progress, capitalism misshapen.

Resumen: El objetivo general de este trabajo es poner a prueba una primera aproximación sobre la evolución y el contexto de la producción de textos de Marx, de su trabajo como un capital a largo plazo, - exclusivamente en el Libro III, y aún más, especialmente la sección de renta de la tierra - que es irreductiblemente marcado por un edificio sin terminar. En esta oportunidad, tenemos la intención de acumular y al detalle algunas consideraciones teóricas y metodológicas, es decir, las precauciones "para evitar malos entendidos", como señaló Marx, llevado a cabo de manera más sistemática en el capítulo 37. La hipótesis central es que la cuestión de la renta de la tierra está hecha de una representación no lineal del desarrollo histórico, especialmente para un enfoque que incluye una crítica de la noción abstracta de progreso y de la relación del desarrollo desigual y combinado, que puede servir como punto de partida para los problemas contemporáneos de la agricultura y el capitalismo, especialmente en los llamados sistemas capitalistas sub-periférica. Dicha construcción descalificar una vez por todas la comprensión de estos pasajes críticos como categorías eternas, típica de las visiones lineales y optimista del positivismo marxista.

Palabras clave: Marx, renta de la tierra, la revisión del progreso, el capitalismo deforme.

Deve-se fundar o conceito de progresso na ideia da catástrofe. Que "tudo continue assim", isto é a catástrofe.

Walter Benjamin (1989: 174).

\section{Notícias de uma obra inacabada}

Voltar à extensa obra de Marx nos conduz definitivamente à aposta em atualizar suas indicações e suas pistas e, quem sabe, em iluminar passagens esquecidas ou obscurecidas, mesmo estando elas frequentemente em pontos secundários. Mergulhar em sua obra permanece uma referência necessária, um ponto de partida indispensável para todo pensamento e toda ação emancipadora. Graças e apesar do desenvolvimento contraditório do pensamento marxista e do mundo moderno, o desejo de voltar a Marx impele, pois, a uma tarefa legítima, desde que não se negligencie um século de história do marxismo, na qual encontramos uma herança diversamente conflituosa e aberta, que revelou sua amplitude lentamente, entre impasses e avanços.

Seja como for, a tarefa parece identificar um obstáculo ainda maior quando se trata da consagrada obra de Marx: $O$ capital. O que se percebeu é que, nas centenas de análises dedicadas exclusivamente a essa obra, poucas ou quase nenhuma atentaram a entender a arquitetura da obra, a evolução dos conceitos, a contextualização da produção do texto, enfim, os entroncamentos que se manifestaram ao longo do percurso do autor. Trata-se, pois, de frisar o caráter fragmentário de uma obra rearranjada, de valorizar sua elaboração teórica, de difícil compreensão, de um retorno não apenas para os conceitos de Marx, mas de um retorno para um modo de pensar que combina 
momentos de método de investigação e método de explicação. Daí, através dos novos problemas do mundo moderno, é que podemos continuar e prolongar sua obra nas suas múltiplas manifestações, imbuída de dar conta da complexidade do real. Tal questão não passou incólume ao marxismo. Em seu encarceramento, Antonio Gramsci, por exemplo, "sacou" logo a diferença entre a obra de um autor que planeja e classifica toda a sua obra, um universo teórico sistêmico, e aquele em que a obra é reapresentada sob diversas formas, por um caráter incompleto e provisório do material reunido. Tal diferença posta em destaque pode ser decisiva para entender mais completamente a totalidade material e filosófica de um autor. Afirma Gramsci (apud BIANCHI, 2008: 35):

Entre as obras do pensador dado, além disso, é preciso distinguir aquelas que ele concluiu e publicou daquelas que permaneceram inéditas, porque não concluídas, e foram publicadas por amigos e discípulos, com revisões, modificações, cortes, ou seja, com uma intervenção ativa do editor. É evidente que o conteúdo desta obra póstuma deve ser tomado com muito discernimento e cautela, porque não pode ser considerado definitivo, mas apenas material ainda em elaboração, ainda provisório; não se pode excluir que essas obras, especialmente se há muito em elaboração sem que o autor não se dedicasse nunca a completá-las (no todo ou em parte), fossem repudiadas pelo autor ou consideradas insatisfatórias.

O conselho de cautela do marxista sardo foi feito justamente em relação às obras relativas a Marx, mas tinha um duplo sentido: se referira também à sua própria obra, especialmente à sua obra carcerária. Trata-se, então, de um trabalho complexo, repensado constantemente, comparando-se com aquilo que Marx atribuiu em suas análises sobre os segredos da extração de mais-valia: há toda uma preparação prévia. $\mathrm{O}$ tempo que conta não é somente a hora do seu ato de produção, mas também como se pensa e se organiza, o esforço todo, de aprendizado e reaprendizado, um acúmulo de ideias.

Destacar essas "lacunas" não significa, por outro lado, afirmar uma ideia esparsa, um não-projeto, que se dispersa e se isola; ao contrário, pois Marx ancora-se em um método específico, uma lógica, um projeto, dos quais emergem categorias decisivas. É em busca de todo o conjunto de seus momentos que deriva o método de Marx, marcado pela Lógica de Hegel, da restituição do todo em suas partes: uma "totalidade relacional e aberta", para juntarmos as expressões cunhadas por Daniel Bensaïd e Henri Lefebvre. Bem entendido, se não levarmos em consideração a gênese e a estrutura da obra que continua a ser um constante desafio aos leitores de Marx e do 
marxismo em geral, o que vai nos restar, portanto, é apenas um amontoado de lugarescomuns, revelando, como afirmou o próprio Marx uma vez, um "grosseiro interesse sobre o tema". O manuscrito em questão foi pensado por quase duas décadas sendo escrito e reescrito inúmeras vezes, em notas de estudos em condição não raro precárias, interrompido em várias ocasiões, planejado inicialmente de uma forma e, com o tempo, passando por intensas modificações ${ }^{1}$. Na academia e nos debates políticos, o último livro d'O capital foi majoritariamente ignorado. Lê-se e comenta-se praticamente apenas o Livro I.

Pois bem: o objetivo mais geral deste texto é ensaiar uma primeira aproximação sobre a evolução e a contextualização da produção do texto de Marx, a partir de sua obra de maior fôlego, $O$ capital - exclusivamente no Livro III e especialmente na seção da renda fundiária -, que está irredutivelmente marcada por uma construção inconclusa. Pretende-se acumular e detalhar algumas considerações teórico-metodológicas, isto é, precauções para "evitar mal-entendidos", tal como assinalou Marx, levadas a cabo mais sistematicamente no capítulo 37. A hipótese central é a de que o tema da renda da terra é construído a partir de uma representação não linear do desenvolvimento histórico, principalmente por uma abordagem que inclui uma crítica da noção abstrata do progresso e da relação de desenvolvimento desigual e combinado, o que pode servir como ponto de partida para os problemas contemporâneos entre agricultura e capitalismo, principalmente nos assim chamados sistemas capitalistas subnacionais periféricos. Tal construção desautorizaria de uma vez por todas a compreensão dessas passagens críticas como categorias eternas, típicas das visões lineares e otimistas do marxismo positivista.

\section{O Livro III e a seção da renda fundiária: avanços e recuos}

Desde sua juventude, Marx dedicou-se a esquadrinhar as fontes teóricas da economia clássica de seu tempo, deixando uma porção significativa de manuscritos, de notas e de fichamentos, de modo a esboçar, assim, suas primeiras considerações sobre obras específicas e suas primeiras ressalvas à escola clássica. Os manuscritos e notas em questão foram interrompidos diversas vezes durante sua trajetória, por razões diversas,

\footnotetext{
1 A evolução da escrita de Marx tornou-se imprescindível para uma aproximação crítica da sua obra, principalmente nos manuscritos que hoje conhecemos como Livro III, no qual Marx discutiu a distribuição da mais-valia entre os capitalistas dentro do sistema capitalista. Para uma instigante análise sobre a repartição dos lucros obtidos e a concorrência entre os próprios capitalistas cf. LUXEMBURGO, 2009.
} 
mas principalmente pela dedicação do pensador alemão a outros temas conjunturais. Parece ter sido uma pista interessante entender a construção do projeto inicial da obra, a partir da averiguação da correspondência com Engels. A troca de opiniões com o amigo acerca da teoria da renda da terra de Ricardo é reveladora. Marx já fornece, na década de 1850, suas principais reservas à maneira como o economista David Ricardo constrói seu conceito sobre a renda da terra. Engels, por seu turno, elogia suas ponderações e, bem-humorado, cunha um novo "título" a Marx: tu és um "economista da renda da terra!".

Segundo as informações de Rosdolsky, Marx ficou por mais ou menos nove anos tentando encontrar a forma expositiva mais adequada para apresentação da crítica da economia política. O primeiro plano elaborado (1857) previa seis "livros" acrescidos de uma "introdução geral"; no caso do tema da propriedade da terra, nesse primeiro momento, ela seria explorada com exclusividade em um dos seis livros. Com o tempo, o plano primeiro foi aos poucos restringido, dissolvendo-se, enxugando-se alguns temas e incorporando o tema da propriedade da terra em outras seções, ou, ainda, combinandose em outros temas. Portanto, de 1857-1866, as mudanças passam a ocorrer. Desde então surgiu o segundo plano (1866), reduzido doravante a quatro livros: a renda da terra, que teria outrora um livro, agora é incorporada não em um livro exclusivo, mas como uma seção, tratando do tema da renda da terra de maneira bem específica. A preocupação é tão somente se ater a "desenvolver a lei geral da renda da terra como ilustração de uma teoria sobre valores e preços de produção" (MARX apud Rosdolsky, 2001: 34).

O manuscrito do terceiro tomo foi redigido em 1864-1865 e, como se sabe, foi editado e parcialmente reformulado por Engels ${ }^{2}$ depois de sua morte. Rosdolsky (2001: 35-36) afiança que é justamente nessa época que há uma nova mudança para o novo plano estrutural. Marx ultrapassou o que havia pré-definido: em vez de se limitar, como

2 O trabalho de redação do terceiro tomo foi, para Engels, "muitas vezes penoso de decifrar" e qualitativamente um trabalho diferente do efetuado no segundo volume. "No caso do terceiro", diz Engels no prefácio ao terceiro tomo, "só se dispunha de uma primeira versão, ainda por cima cheia de lacunas. Em regra, a parte inicial de cada uma das seções individuais estava elaborada de modo bastante cuidadoso, estando também estilisticamente acabada. Mas quando se avançava, tanto mais a redação se reduzia a um simples esboço e apresentava mais lacunas, tanto maior ponto de digressões sobre pontos secundários, surgidos ao longo da investigação e cujo local definitivo ficou dependente de um ordenamento ulterior, tanto maiores e intricados se tornavam os períodos em que se expressavam os pensamentos anotados in status nascendi" (ENGELS, 1983: 6, grifos meus). Nossa escolha em aprofundar o capítulo de entrada da renda da terra deve-se a esse comentário de Engels e, nesse sentido, é corroborada por Rosdolsky. No entanto, em outras apresentações, Engels sempre tentou propor que $O$ capital é uma obra acabada. Há, portanto, que controlar essa ponderação para não resvalarmos em um sistema fechado. Para uma leitura aberta d'O Capital cf. Bensaïd 1995; 1999. 
havia pensado antes, a se dedicar à "diferença entre valores e preços de produção", isto é, a expor a renda absoluta, Marx estende a questão e detalha a renda diferencial da teoria de Ricardo $^{3}$; desenvolve igualmente um capítulo dedicado à renda de terrenos destinados à construção, à renda das minas e o preço da terra e principalmente a uma investigação profunda sobre a "gênese da renda fundiária capitalista"4. Todavia, embora o tema tivesse um avanço significativo, o tratamento sistemático da propriedade da terra estaria definitivamente fora de seus planos, o que se justifica logo na primeira frase da seção VI: "a análise da propriedade fundiária em suas diferentes formas históricas está além dos limites desta obra" (MARX, 1983: 123). Por outro lado, no prefácio ao terceiro tomo d'O capital, Engels nota que "a seção da renda fundiária estava desenvolvida de maneira muito mais completa, ainda que de modo algum ordenada" (ENGELS, 1983: 8, grifos meus), e havia uma espécie de análise da renda em relação às tabelas sobre a renda diferencial II que não tinha sequer sido examinada. As diferentes formas de propriedade privada eram, no entanto, estudadas por Marx. Em relação a esse fato, Engels revela que "Marx tinha feito, nos anos [18] 70, estudos especiais totalmente novos": as publicações sobre a propriedade fundiária foram conseguidas pelos amigos russos de Marx, que as "puseram a sua disposição em forma tão completa quanto se poderia desejar" e "estudados por anos por Marx no idioma original: deles extraiu citações, que tinha intenção de utilizar na reelaboração dessa seção" (Idem, Ibidem). Esse fato não deve ser de forma alguma ignorado, pois a sua importância poderia ser central sobre a questão da renda da terra:

Dada a variedade de forma, tanto da propriedade fundiária quanto da exploração dos produtores agrícolas na Rússia, na seção sobre a renda fundiária deveria desempenhar o mesmo papel que, no Livro Primeiro, a Inglaterra desempenhou no que tange ao trabalho assalariado industrial (ENGELS, 1983: 8-9).

Notemos que a construção que foi publicada acerca da renda da terra, assim como as outras seções do livro, são considerações tendenciais, isto é, processos e devires particulares do conjunto processual incompleto.

\section{A renda fundiária segundo Marx: preliminares para evitar "mal-entendidos"}

\footnotetext{
3 Em pelo menos dois textos o geógrafo Ariovaldo Umbelino de Oliveira dedicou-se a aprofundar a concepção acerca da renda da terra diferencial que está presente no texto de Marx. Cf. OLIVEIRA, $1984 ; 1985$.

Trata-se do capítulo 47 (1983: 245-266).
} 
Em Marx (1983), os desdobramentos sócio-espaciais da subordinação da produção material aos ditames do capitalismo podem ser vistos no campo. Como de praxe, o pensador alemão, para desenvolver sua análise sobre as relações do capitalismo e a agricultura, parte de uma hipótese metodológica da qual decorre uma dominação completa do capitalismo sobre a agricultura. Assim, está suposto também que se "o modo de produção capitalista se assenhoreou da agricultura implica que ele domina todas as esferas de produção e da sociedade civil” (MARX, 1983: 123). Sublinha constantemente os limites de seu empreendimento, ou seja, até onde deseja ir e até onde deseja recuar: "Limitamo-nos, portanto, exclusivamente ao investimento de capital na agricultura propriamente dita, ou seja, na produção dos principais produtos de origem vegetal, dos quais vive uma população" (Idem, Ibidem). Marx vai estudar o propósito da propriedade fundiária procurando examinar as relações específicas de produção e de circulação na agricultura, sem o que, para ele, a análise do capital seria insuficiente. Isso tudo, segundo Marx, para "evitar mal-entendidos" - vale ressaltar que o capítulo 37 é dedicado precisamente a salientar em quais pontos o capítulo será desenvolvido e em quais pressupostos metodológicos está baseado.

No modo de produção capitalista, segundo Marx, os genuínos agricultores são assalariados e o arrendatário, aquele que investe seu capital em um espaço específico da produção, paga ao proprietário da terra uma soma de dinheiro para poder aplicar seu capital no solo. Daí a denominação de renda fundiária: "Ela [é] paga por todo tempo durante o qual o dono da terra emprestou, alugou o solo do arrendatário. A renda é, portanto, a forma em que a propriedade fundiária se realiza economicamente, se valoriza" (MARX, 1983: 126). Temos, nessa missiva, uma tensão multifacetada não de duas classes, mas de três classes na sociedade moderna: "Temos aqui reunidas e confrontadas as três classes que constituem o quadro da sociedade moderna: trabalhador assalariado, capitalistas industriais, proprietário fundiário" (Idem, Ibidem). Sob esse prisma, procura destacar o que seria renda fundiária, demonstrando o que ocorre quando o arrendatário paga ao proprietário, por um determinado período estipulado contratualmente, pelo uso da terra. Este, por sua vez, é o beneficiário do que foi realizado na propriedade em benfeitorias, além do que foi pago com o arrendamento das terras, significando que as melhorias realizadas servem como suporte para determinar o valor da propriedade acrescido de juros implícitos. Ou seja, o arrendatário recebe duplamente pela renda fundiária, contratualmente estipulada, e mais os juros que nada 
têm a ver com o processo de arrendamento, incorporando-os a sua renda. Em poucas palavras, é o arrendatário, e não o proprietário, que investe permanentemente ou transitoriamente ao melhoramento no solo como, por exemplo, em boa drenagem, em bastante adubo, servindo a acrescer o valor da propriedade, mas o lucro desse empreendimento fica com o proprietário das terras. Quando, então, termina o contrato, cada vez mais em um período mais curto, entre o proprietário de terra e o arrendatário, "as melhorias incorporadas ao solo passam a pertencer ao dono deste, como acidente inseparável da substância, o solo" (Idem, Ibidem). Um novo contrato que pode ser, vale dizer, com o mesmo arrendatário que depositou um investimento, terá agora a renda acrescentada (ou aumentada) dos "juros pelo capital incorporado ao solo" ou, em outros termos, na proporção do valor acrescido da terra em virtude dessas melhorias. O segredo, então, desvela-se totalmente acerca do enriquecimento constante dos proprietários fundiários em detrimento dos pequenos agricultores. Isso evidentemente não fez com que o arrendatário não resistisse a essa lógica. Marx diz que é exatamente a resistência dos arrendatários "um dos maiores empecilhos ao desenvolvimento racional da agricultura, pois o arrendatário evita todas as melhorias e gastos cujo retorno integral não pode ser esperado durante o prazo de arrendamento" (MARX, 1983: 127, grifo nosso).

Existe também uma outra forma em que a renda fundiária pode confundir-se com o juro, não reconhecendo que a renda fundiária "pode existir e existe de modo puro, sem acréscimo de nenhum juro pelo capital incorporado ao solo" (MARX, 1983: 128). É o momento em que o arrendatário paga anualmente uma certa quantia pelo arrendamento configurado em um período determinado nos custos pagos pelo proprietário pela compra da propriedade. Ou seja, após o período estabelecido contratualmente entre as partes (proprietário e arrendatário), o proprietário terá reposto o dinheiro empregado através das receitas do arrendamento; entretanto, mantendo a propriedade sob seus domínios e, como foi visto anteriormente, com valor adicional das melhorias realizadas, o que vai aumentar o valor da terra: "Daí se deduz que, pressupondo-se a renda fundiária como uma grandeza constante, o preço das terras pode subir ou descer na razão inversa da subida ou queda de juros" (MARX, 1983: 129).

A propriedade privada da terra transforma-se, pois, em uma mercadoria de grande investimento: 
[...] a propriedade fundiária é considerada uma forma particularmente nobre da propriedade e compra dela, além disso, um investimento especialmente seguro de capital, então a taxa de juros, pela qual se compra a renda fundiária, é geralmente mais baixa do que em outros investimentos de capital feitos a longo prazo (MARX, 1983: 129130).

A terra passa a ser comprada e vendida como qualquer outra mercadoria. Mas, atenção: assinalar esse tipo de compreensão não faz com que Marx partilhe da argumentação - disseminada pelos economistas clássicos - segundo a qual o processo de mercantilização da terra ocorreria sem afetar os arrendatários. Contrariamente à naturalização das relações sociais, Marx expõe a exploração gradual e permanente dos proprietários sobre os arrendatários, ancorado desenvolvimento real das relações de conflito daqueles sobre estes que impulsionaram o crescimento do seu capital, justificando, desse modo, a propriedade fundiária. O reconhecimento dessa tensão histórica em sujeitos sociais diversos assinalaria uma capacidade teórica de recuperar as tradições de luta das classes populares exploradas e descobrir a potencialidade de sujeitos sociais que estavam sendo explorados em um desenvolvimento do capitalismo diverso à Europa ocidental.

Com esse mote, se levarmos até as últimas consequências uma das frases mais citadas, redigida a quatro punhos pelos bateleiros do materialismo histórico, a história de todas as sociedades até agora tem sido a história das lutas de classe, a contraposição entre opressor e oprimido poder-se-á sentir em todos os modos históricos de produção capitalistas e não-capitalistas. Nesse sentido o relato de Thompson, em Senhores e Caçadores, é bastante esclarecedor: o historiador reconstrói e recupera as lutas explosivas do passado camponês inglês, descobrindo um mundo subterrâneo de tradição de insurreição em relação aos impasses sociais e morais em torno das origens de uma certa Lei $\mathrm{Negra}^{5}$, decretada em maio de 1723, importante lei na história jurídica

\footnotetext{
5 Em linhas gerais, a decretação da Lei Negra, tal como afiança Thompson, estava longe de ser uma controvérsia "nacional"; no entanto, há evidências de "alguns distúrbios locais": tais ocorridos estavam restritos em um espaço específico, como em áreas florestais ou propriedades particulares através de denúncias de caça noturna e perseguição de veados. Aprovada em maio de 1723, a Lei Negra tinha como função proteger as florestas e os bosques ingleses contra os "caçadores clandestinos" e evitar "desordens sociais" que ocorriam especialmente nas regiões em torno de Windsor e de Hampshire. Ela serviu, em grande medida, aos interesses dos proprietários, especialmente à oligarquia Whig, que adquiriu, com essa nova lei, um importante instrumento para a defesa de sua propriedade "imóvel" (propriedades rurais, parques, florestas e a própria casa) e de suas propriedades móveis (gado, animais selvagens, lenha, turfa etc.). No entanto, a Lei foi ampliada por sucessivas decisões mais abrangentes, gerando uma lei cujo estatuto estava mal formulado: "a Lei estava esboçada de modo tão vago que se converteu em terreno prolífico para decisões judiciais cada vez mais abrangentes" (THOMPSON, 1987: 23).
} 
do século 18 na Inglaterra. Esse objeto de estudo seria uma expressão histórica de formação da noção moderna de propriedade, ou melhor, um meio de consolidação da noção moderna de propriedade que começa a assumir e a se processar na Inglaterra dos séculos 17 e 18. É exatamente nesse meio que há uma tensão moral e material de concepções de direitos e de costumes feudais de pertencimento entre uma visão moderna em matéria de propriedade e de sua regulação jurídica. Isso é feito pela mudança radical do espaço social dos camponeses e/ou moradores do campo que são expropriados conforme a utilização em larga escala das cercas.

\section{Crítica do progresso e ênfase da particularidade histórica como método de análise}

O sociólogo franco-brasileiro Michael Löwy (2000) apontou que o pensamento de Marx é dividido por uma tensão entre duas concepções diferentes da dialética do progresso. A primeira, uma dialética fechada - por um fim já predeterminado - que legitima o progresso "enquanto espiral ascendente" e que, nos termos de Georg Simmel, "exclui a contingência" ("o progresso é o desenvolvimento da ordem”, segundo a expressão de Auguste Comte). A segunda, por outro lado, trata de uma dialética aberta, pois enuncia as calamidades sociais de cada progresso econômico, a sua impiedosa violência contra os vencidos. No capítulo analisado, há passagens que corroboram com essa segunda visão. Logo no início, quando Marx escreve sobre o monopólio da propriedade fundiária, assegura que este

[...] é um pressuposto histórico e continua sendo o fundamento do modo de produção capitalista, bem como de todos os modos de produção anteriores que se baseiam, de uma maneira ou de outra, na exploração das massas. Mas a forma em que o incipiente modo de produção capitalista encontra a propriedade fundiária não lhe é adequada. Só ele mesmo cria a forma que lhe é adequada, por meio da subordinação da agricultura (MARX, 1983:124-125, grifos meus).

A atribuição da não adequação entre propriedade fundiária e modo de produção capitalista revela um tempo social discordante. Adiante, na mesma citação, apura-se um novo elemento que aponta a face de uma dialética aberta do progresso: ele reconhece os horrores da dominação, de todos os modos de produção antes do capitalismo e no 
próprio capitalismo, o que faz com que a resistência e a luta por parte das camadas plebeias, em qualquer espaço e tempo histórico, sejam legítimas.

Em outro trecho, a dialética aberta do progresso parece ficar mais clara, na medida em que procura trazer à tona uma contradição da subordinação da agricultura ao capital, a qual o curso do progresso exerce duas faces contraditórias:

A racionalização da agricultura permitindo que essa possa, afinal, ser exercida socialmente, por um lado, e a redução da propriedade fundiária ad absurdum, por outro, são estes os grandes méritos de produção capitalista. Como seus demais progressos históricos, também este foi obtido de início mediante a total pauperização dos produtos diretos (MARX, 1983: 125, grifos meus).

Essa passagem de Marx, a qual atribuiu à locomotiva do progresso histórico uma face de pauperização, mostra claramente a natureza contraditória do progresso capitalista e, nesse sentido, não ignora de forma alguma seu lado catastrófico, sua natureza que exige sacrifícios humanos. É evidente, como ressaltado, que se trata de um problema longe de encontrar uma resposta unívoca em Marx. Em todo caso, por mais que não se importasse em falar das supostas "condições excepcionais" nesse capítulo, é interessante a perspectiva de Marx, por exemplo, sobre as condições específicas da Irlanda desautorizando que seus leitores o levassem ao pé da letra; ou, pior, apreendessem n' $O$ capital uma filosofia na qual o curso da historia universal fosse previamente traçado. A incorporação da Irlanda (e, vale lembrar, provável e central incorporação do estudo da renda da terra no caso russo o qual Marx não conseguiu concluir por mais que desejasse) como um exemplo não-contemporâneo no texto não é fortuita ${ }^{6}$. Trata-se de marcar a especificidade de seu estudo que tem como principal fonte o caso da Inglaterra - "que a sociedade moderna, em sua estrutura econômica, está desenvolvida ao máximo, de modo mais clássico" - e a Europa ocidental.

A diversificação do campo agrícola em relação ao campo do modo de produção capitalista permite não apenas que se fale em agricultura contemporânea, como um “capitalismo sem capitalistas", segundo a expressão de Vergopoulos (1977), mas também permite compreender o caráter necessário das deformidades que aparecem

6 Bensaïd (1999) enuncia que, nos rascunhos introdutórios aos Grundrisse, Marx introduz um texto programático, uma nova escrita da história, que inclui a relação de desenvolvimento desigual e uma abordagem crítica à noção abstrata do progresso, registrando "pontos telegráficos" sob a forma de "nota bene para mencionar e não esquecer": "[1] A relação desigual entre o desenvolvimento da produção material (...). [2] De uma maneira geral, não usar o conceito de progresso sob a forma habitual" (MARX apud BENSAÏD, 1999: 39). Para uma análise na hipótese levada à cabo por Bensaïd acerca da invenção de uma nova escrita da história cf. RUBBO, 2011. 
sobre o corpo social do capital. Segundo Marx, a renda fundiária que era pressuposta ao longo do texto como o modo de propriedade fundiária correspondente ao modo de produção capitalista, no caso da Irlanda, não corresponde, portanto, a essa suposição. As condições específicas da renda fundiária na Irlanda prevalecem "sem que exista o próprio modo de produção capitalista, sem que o próprio arrendatário seja um capitalista industrial ou seu modo de cultivar seja capitalista" (MARX, 1983: 131).

Além disso, a composição orgânica do capital, constituída por apenas duas classes sociais - burguesia e proletariado -, dificultaria a compreensão dos tempos sociais discordantes pelos quais o capitalismo se reproduz: o capítulo da fórmula trinitária, nesse sentido, parece ser uma fonte interessante de estágios de intermediações e combinações, assim como o capítulo interrompido sobre as classes também parece ser uma fonte luminosa:

Os proprietários de mera força de trabalho, os proprietários de capital e os proprietários da terra, cujas respectivas fontes de rendimento são o salário, o lucro e a renda fundiária, portanto, assalariados, capitalistas e proprietários da terra, constituem as três grandes classes da sociedade moderna, que se baseia no modo de produção capitalista (MARX, 1983: 317).

Com isso, evidentemente, não se está afirmando de modo algum uma resposta acabada para um tema que obviamente deve ser confeccionado de maneira mais profunda; no entanto, trata-se apenas de pistas para nossas indagações ${ }^{7}$. Indagações estas que não estão procurando um paradigma "correto" do progresso em Marx. Como bem disse Balibar (1995: 102-103, grifo do autor) "mais do que ler em Marx a ilustração (entre outras) de uma ideia geral, o que é interessante é utilizá-lo como um revelador, um analisador dos problemas inerentes a uma tal ideia”.

\section{Disformidade e desenvolvimento desigual e combinado: o capitalismo (periférico) fora do eixo}

No caso específico que se acabou de estudar neste texto, por mais que o próprio Marx assentasse, por um lado, suas prerrogativas em deslindar acerca da renda fundiária - especificamente econômica - como propriedade fundiária na base do modo de

\footnotetext{
Ainda que as indicações a partir dos textos de Marx sejam muito rudimentares para pensar a América Latina, Bianchi (2010: 178-185) refaz o itinerário de Marx assentando-se na hipótese de que, em suas análises sobre EUA, México, Índia, Irlanda, Rússia, ocorre uma alteração de seu pensamento, uma nova atitude, que marca uma ruptura decisiva com toda filosofia da história do progresso linear e homogêneo, servindo, assim, como ponto de partida para aprendermos a interpretar a particularidade do desenvolvimento capitalista na América Latina.
} 
produção capitalista e tenha pretendido partir disso, conseguiu, por outro lado, destacar mesmo que parcialmente as contratendências da renda terra. Isto é, por existirem diversas formas sociais que a renda da terra pode apresentar em uma dada situação concreta específica, a matriz interpretativa não segue um desenvolvimento igual das forças produtivas como motor único de explicação e da qual todas as sociedades devem passar por estágios semelhantes de desenvolvimento.

Mais ainda: as pistas podem contribuir para apreender a especificidade da "evolução truncada" contemporânea dos assim chamados sistemas capitalistas subnacionais periféricos ${ }^{8}$. Para Ariovaldo Umbelino de Oliveira, uma concepção teórica crítica de compreensão do desenvolvimento do capitalismo no campo seria caracterizada por um processo contraditório e combinado:

[...] isso quer dizer que, ao mesmo tempo que esse capitalismo avança reproduzindo relações especificamente capitalistas (implantando o trabalho assalariado pela presença no campo do boia-fria), ele (o capitalismo) produz também, igual e contraditoriamente, relações camponesas de produção (pela presença e aumento de trabalho familiar do campo) (OLIVEIRA, 1999: 73) ${ }^{9}$.

Trata-se de uma análise que leva em conta a mútua relação das formações centrais e (semi) periféricas no sistema capitalista mundial, afinal, a formação periférica tem lugar na divisão internacional do trabalho capitalista, mantendo-o em uma situação de subordinação financeira. De fato, posto e reposto, a compreensão que concebe a história como o desenvolvimento das forças produtivas e das alterações que tal desenvolvimento promove nas relações sociais pode levar a formas equivocadas. Evidentemente, o desenvolvimento das forças produtivas tem um papel importante nos processos sociais e no alcance das lutas políticas, mas transformá-lo em sinônimo de locomotiva da história universal é um sinal negativo de uma compreensão adequada às relações reais:

\footnotetext{
Para uma análise entre intelectuais acadêmicos brasileiros que constituíram a lei do desenvolvimento desigual e combinado como matriz interpretativa acerca dos países que chegaram tardiamente ao capitalismo industrial cf. DEMIER, 2007.

Recapitulando sua análise acerca do processo da expansão capitalista no Brasil em Crítica à razão dualista e levando em conta o processo contraditório e combinado, o sociólogo Chico de Oliveira desautorizou e apontou as falácias da tese do setor atrasado como obstáculo ao desenvolvimento, sustentando a hipótese segunda a qual "a agricultura atrasada financiava a agricultura moderna e industrialização". As formas de subsistência seriam de forma decisiva, "o motor de rebaixamento do custo de reprodução da força de trabalho urbana" (OLIVEIRA, 2003:129).
} 
Não é preciso que as forças produtivas se desenvolvam em cada estabelecimento agrícola ou industrial, em cada sítio ou oficina, a ponto de impor, a ponto de impor a necessidade das relações caracteristicamente capitalistas de produção, de impor o trabalho assalariado, para que o capital estenda suas contradições e sua violência aos vários ramos da produção no campo e na cidade. [...] A concepção de Marx com a qual Marx trabalhava não era do desenvolvimento igual, e sim a do desenvolvimento desigual. É o que permite entender transformações sociais profundas em sociedade, desse ponto de vista, atrasadas (MARTINS, 1981: 14).

O sistema capitalista contemporâneo desenvolve velhas formas ressuscitadas e reconstituidas, um laboratório de disformidade crescente, principalmente na agricultura, como mostra Vergopoulos (1977). O capitalismo não faz com que o mundo rural desapareça, o que ocorre é uma reinvenção de seus sistemas sociais, na complexidade de uma temporalidade agrária múltipla.

O poema Édipo e seu enigma, de Jorge Luis Borges, exprime a necessidade de descortinar as intermitências e os contratempos da relação entre industrialização, agricultura e capitalismo: “.... Mas eu seria aniquilado / Se deixasse minha lei disforme revelar-me. / Clemente, Deus me deu o progresso e o esquecimento". Cabe-nos decifrar, e decifrar significa quebrar o espelho da temporalidade uniforme, o caminho que consiste em recuperar a narrativa da memória coletiva e as lutas sociais contemporâneas, em recuperar oportunidades estratégicas, e em repensar a emancipação social do ponto de vista da multiplicidade dos sujeitos coletivos e individuais contemporâneos.

E é tarefa de um marxismo crítico como expressão prática de uma teoria aberta do conflito (BENSAÏD, 1999); um movimento de pensamento unificador; um conhecimento racional do mundo - ou, na expressão intempestiva de Walter Benjamin, que "avança com o machado da razão" - e que constantemente se aprofunda e se ultrapassa a si mesmo. O capital segue essa lógica e em seu conjunto se encontra em pleno devir. Não se trata, portanto, de um sistema acabado e completo, mas, ao contrário, de uma obra provisória, que era constantemente reconstruída. É possível avançar nas indicações, sem querer apressadamente defini-las e classificá-las como fazem as sociologias vulgares. Conforme um plano traçado, é possível uma reconstrução das formulações teóricas, dos escritos, da aquisição das ideias, da sua formação, de sua correspondência e de suas contradições. Graças a essas precauções, podemos encontrar um Marx expressivo na sua delicada complexidade, tornado acessível, mas nunca simplificado. A inquietude de Marx e sua capacidade de 
compreender e questionar as coisas, inclusive pelo aspecto inesperado, faz dele um estímulo para renovar produções, evitando a tendência perigosa de transformá-lo em dogma.

Posto e resposto, em tempos de derrocada dos processos de desenvolvimento e do progresso, a insistência de uma noção universalista do progresso oculta a identificação (terrível) de modernidade/barbárie ou progresso/catástrofe ${ }^{10}$. Assim, os camponeses sem terra, os despejos violentos das comunidades indígenas e quilombolas, o trabalho não pago, semipago e pago de modo ultrapassado no campo não são prova do atraso do país, mas de sua forma atroz de modernização.

\section{Bibliografia consultada}

BALIBAR, Étienne. A filosofia de Marx. Rio de Janeiro: Jorge Zahar, 1995.

BENJAMIN, Walter. Charles Baudelaire: um lírico no auge do capitalismo. São Paulo: Brasiliense, 1989.

BENSAÏD, Daniel. Marx, o intempestivo: grandezas e misérias de uma aventura crítica. Rio de Janeiro: Civilização Brasileira, 1999.

La discordance des temps: essais sur les crises, les classes, l'histoire. Paris: Passion,1995.

BIANCHI, Álvaro. “O marxismo fora do lugar”. Política \& Sociedade, Florianópolis, v.9, n.16, 2010, pp. 177-203.

. O Laboratório de Gramsci: Filosofia, História e Política. São Paulo: Alameda, 2008.

BORGES, Jorge Luis. O outro, o mesmo. São Paulo: Companhia das Letras, 2009.

DEMIER, Felipe. “A lei do desenvolvimento desigual e combinado de Leon Trotsky e a intelectualidade brasileira”. Outubro. São Paulo, n.16, 2007, pp. 75-107.

\footnotetext{
10 "Aqui [no Brasil] a modernidade produz as metrópoles, que industrializa e mundializa à economia nacional, internacionalizando a burguesia nacional, soldando seu lugar na economia mundial, mas prossegue também, produzindo a exclusão dos pobres na cidade e no campo. Esta exclusão leva a miséria parte expressiva dos camponeses e trabalhadores brasileiros. [...] Não se trata, pois de um retorno ao passado, mas, de um encontro com o futuro" (OLIVEIRA, 2003: 114).
} 
ENGELS, Friedrich. Prefácio. In: MARX, Karl. O capital: crítica da economia política. V. 3 (tomo I e II). O processo global da produção capitalista. São Paulo: Abril Cultural, 1983.

LÖWY, Michael. "A dialética marxista do progresso". In: LÖWY, Michael \& BENSAÏD, Daniel. Marxismo, Modernidade e Utopia. São Paulo: Xamã, 2000, pp. 77-83.

LUXEMBURGO, Rosa. "O segundo e o terceiro volume d'O capital". Crítica Marxista. São Paulo, n.29, 2009, pp. 135-143.

MARTINS, José de Souza. Os camponeses e a política do Brasil. Rio de Janeiro: Vozes, 1981.

MARX, Karl. O capital: crítica da economia política. V. 3 (tomo I e II): O processo global da produção capitalista. São Paulo: Abril Cultural, 1983.

OLIVEIRA, Francisco de. Crítica à razão dualista / O ornitorrinco. São Paulo: Boitempo, 2003.

OLIVEIRA, Ariovaldo Umbelino de. Renda da terra. Orientação, n.5. IGEOG/USP, São Paulo, 1984, p. 94-95.

. Renda da terra diferencial I e II. Orientação, n.6, IGEOG/USP, São Paulo, 1985, p. 93-104.

. “A geografia agrária e as transformações territoriais recentes no campo brasileiro". CARLOS, A. F. A. (org.). Novos Caminhos da Geografia. São Paulo: Contexto, 1999.

- "Barbárie e Modernidade: as transformações no campo e o agronegócio no Brasil”. Terra Livre. São Paulo, v.2, n.21, 2003, pp. 113-156.

ROSDOLSKY, Roman. Estrutura e Gênese de $\boldsymbol{O}$ capital de Karl Marx. Rio de Janeiro: Eduerj/Contraponto, 2001.

RUBBO, Deni I. A. "Por uma crítica da razão histórica: o capítulo das bifurcações na concepção da história em Daniel Bensaï’”. História \& Luta de Classes. Paraná, n.11, ano 7, 2011, p.77-83.

THOMPSON, E. P. Senhores \& Caçadores: a origem da Lei Negra. Rio de Janeiro: Paz e Terra, 1987. 
VERGOPOULOS, Kostas. Capitalismo disforme (o caso da agricultura no capitalismo). In: AMIN, Samir; VERGOPOULOS, Kostas. A questão agrária e o capitalismo. Rio de Janeiro: Paz e Terra, 1977. 